\title{
Explaining urease specificity towards nickel: a re-analysis of its proposed mechanism
}

\author{
Millena P. Ferreira, Caio B. De Castro, Caterina G. C. Marques Netto* \\ Rod. Washington Luiz, km 235 s/n, Departamento de Química, Universidade Federal de \\ São Carlos (UFSCar) - São Carlos, Brazil \\ *caterina@ufscar.br
}

\begin{abstract}
Urease is a binuclear metalloenzyme extremely selective towards nickel, exhibiting a remarkable rate enhancement of the catalytic reaction. The accepted mechanism proposal for urease describes the coordination of urea to both nickel centers in an $\mathrm{O}, \mathrm{N}$ bridged mode, enabling the attack of the carbonyl by a bridged hydroxide present between the metallic centers. However, the substitution of nickel by other metals $\left(\mathrm{Fe}^{2+}\right.$, $\mathrm{Co}^{2+}, \mathrm{Mn}^{2+}, \mathrm{Zn}^{2+}$, and $\mathrm{Cu}^{2+}$ ) significantly reduces urease's catalytic efficiency. The proposed mechanism cannot explain this difference in activity since it does not follow a rational nucleophilicity scale. After a careful analysis of the literature data on thermodynamics, kinetics, inhibition, and mutations, we verified that by analyzing the mechanism from a different angle, another pathway is most likely occurring. This mechanism can explain urease's selectivity towards nickel and all the data present in the literature, gathering almost a century of study about this enzyme.
\end{abstract}

Keywords: urease, mechanism, metal selectivity, water exchange rate 


\section{Introduction}

Urease, an enzyme responsible for the hydrolysis of urea into ammonia and carbon dioxide, has a strict selectivity towards nickel. Metal selectivity/promiscuity of a metalloenzyme is determined by an orchestration of multiple factors such as hard/soft interaction, Irving-Williams series, and the environmental and intracellular concentration of the metal. ${ }^{1}$ Also, the catalytic role of the metal is highly conserved in an enzyme mechanism within the same superfamily, ${ }^{2}$ contributing to the design of mechanism proposals of different enzymes.

Owing to the classification of urease as a member of the TIM barrel amidohydrolase superfamily, its mechanism proposal can be compared to other enzymes of this superfamily. ${ }^{3}$ The best comparison within enzymes in this family can be performed between urease and dihydroorotase (DHO), due to the similarity of their active sites. For instance, the active site of urease accommodates one pseudo octahedral (Ni2) and a five coordinated (Ni1) nickel center coordinated to two histidine residues, plus a terminal water or an asparagine residue (Figure 1A). ${ }^{4,5}$ The nickel centers are also bridged by a carbamylated lysine and a hydroxide. In DHO, its active site bears two zinc ions similarly coordinated to the nickel centers in urease active site. The crystallization of $\mathrm{DHO}$ in a $\mathrm{pH}$ that enables the direct and reverse reactions, allowed the simultaneous visualization of the interaction between the protein, substrate, and product at the same time. ${ }^{6}$ In the crystal structure, the substrate dihydroorotate interacts through the amide carbonyl to the tetracoordinate metal center, aiding the amide bond polarization. The carbonyl attack was observed to occur by the bridged hydroxide owing to its favorable orientation. ${ }^{6}$ Hence, in the urease mechanism, it is proposed that three water molecules dissociate from the active site before urea coordination, ${ }^{7}$ allowing an $\mathrm{O}$, $\mathrm{N}$ bridged coordination mode between both nickel centers (Figure $1 \mathrm{~B}$ ), ${ }^{8}$ as shown 
in the urea-urease crystal structure. ${ }^{9}$ However, despite the notion that urease's mechanism is already determined, ${ }^{10}$ it is evident that it still must be debated since it cannot explain urease's catalytic behavior. For instance, when the nickel centers in urease are exchanged by $\mathrm{Fe}^{2+},{ }^{11} \mathrm{Co}^{2+}$ or $\mathrm{Mn}^{2+}$, only $2 \%$ of the restored $\mathrm{Ni}^{2+-}$ enzyme activity is observed, whereas the exchange by $\mathrm{Zn}^{2+}$ or $\mathrm{Cu}^{2+}$ completely inactivates it. ${ }^{12}$ Therefore, if the hydroxyl bridging both metal centers is the nucleophile, the change in activity should follow the order of nucleophilicity. ${ }^{13}$ In the case of DHO, the substitution of $\mathrm{Zn}^{2+}$ by $\mathrm{Co}^{2+}$ reduces the $k_{\mathrm{cat}}$ of $\mathrm{DHO}$ to $15 \%$ of its original $k_{\mathrm{cat}}$, related to a change in the $\mathrm{p} K_{a}$ of the bridged hydroxyl from 5.8 to 6.9 , decreasing the nucleophilicity of the bridged hydroxyl of the $\mathrm{Co}^{2+}$-substituted $\mathrm{DHO}$ at the same $\mathrm{pH}$, and increasing its activity at a higher $\mathrm{pH} .{ }^{14}$ However, the observed decay in $k_{\text {cat }}$ by metal substitution in urease does not follow a nucleophilic order since the determined $\mathrm{p} K_{\mathrm{as}}$ of the nucleophile $\left(\mathrm{Mn}^{2+-}\right.$ urease:pK $K_{\mathrm{a} 2}$ of 9.2 and $\mathrm{Co}^{2+}$-urease: $\mathrm{p} K_{\mathrm{a} 2}$ of 9.1) are similar to the one observed in the native enzyme $\left(\mathrm{p} K_{\mathrm{a} 2}\right.$ of 8.9$) .{ }^{15}$ Therefore, another factor rather than just nucleophilicity is governing urease catalysis.
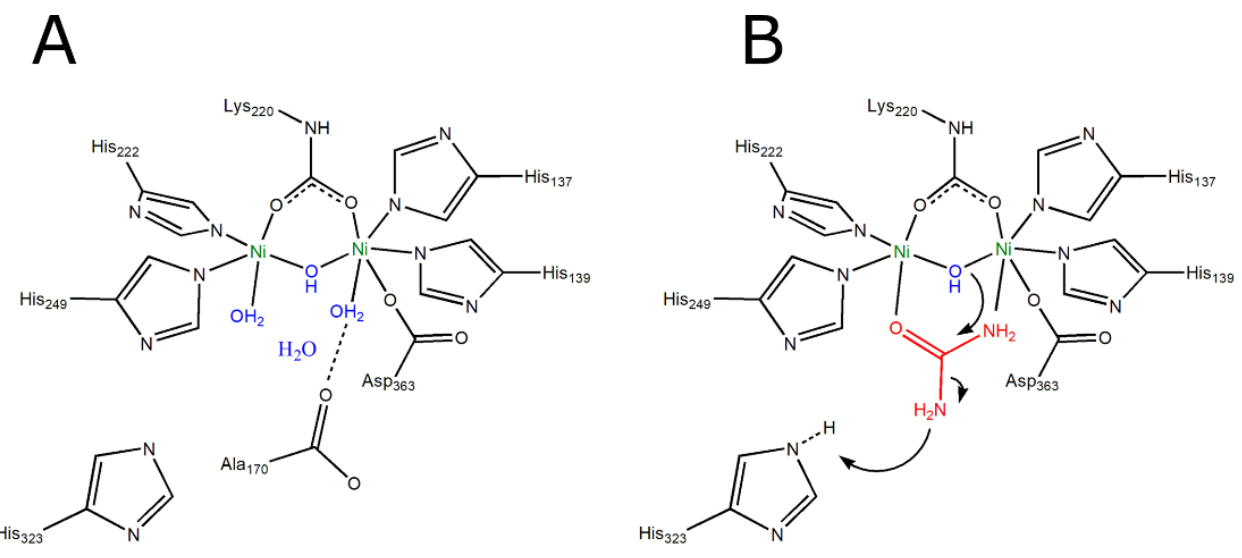

Figure 1. Active site of urease (A) and most accepted mechanism of urease enzyme (B). 
Interestingly, the water exchange rate $\left(k_{\mathrm{ex}}\right)$ measures the speed of the reaction of ligand substitution at an aqueous metal. ${ }^{16}$ Hence, all reactions involving the replacement of strongly bond hydration water from the first coordination sphere are governed by water exchange kinetics. It was found that there is flexibility in the hydration layer of $\mathrm{Mg}^{2+}$ when the water exchange time is greater than the folding of nucleic acids, enabling the bond waters to exchange with the bulk. ${ }^{17}$ Moreover, the first hydration shell of a cation is affected by the chemical nature of the ion, with water exchange rates depending on the ion-water strength, ${ }^{18}$ and stronger interactions determining the exchange dynamics by the hydration shell dynamics. ${ }^{19}$ For instance, Remsing and coworkers have demonstrated that frustrated hydrated cations exhibit greater fluctuations concerning unfrustrated systems, playing a critical role in solvent-mediated processes. ${ }^{20}$ Enzyme active sites can also be perceived as frustrated hydrated systems, ${ }^{21}$ owing to their intrinsic pocket nature. It is known that different cations can influence the mean lifetime of water molecules in the first coordination shell, varying in more than 18 orders of magnitude, ${ }^{22}$ but can this variance be related to the observed mechanism of many metalloenzymes? Here we will analyze the thermodynamics, kinetics, inhibition, and mutations data about urease and will demonstrate that by acknowledging the existence of competition between $k_{\text {cat }}$ and $k_{\text {ex }}$, the mechanism can be redesigned to a proposal able to explain why urease required nickel to function properly.

\section{Analysis of urease mechanism based on thermodynamic and kinetics}

To understand the urease mechanism, we must analyze all factors governing the reaction. Urease has two nickel centers, each coordinated to two histidine residues, one water molecule, a carbamylated lysine, and a bridged hydroxide. $\mathrm{Ni}(2)$ is also coordinated to an aspartate, resulting in an asymmetric coordination number for the 
nickel ions. $\mathrm{Ni}(1)$ is penta coordinated and $\mathrm{Ni}(2)$ is hexacoordinated. The overall charge of the active site complex is zero and partially, one, owing to the resonance structure of carbamate. ${ }^{23}$ The charge of the active site complex and the entering substrate will govern kinetics, as will be explained further on.

It is known that any reaction of ligand substitution is always preceded by the entry of the ligand into the second coordination sphere of water molecules to form an encounter complex $M(L)_{n} \cdot X$, which is further converted to $M\left(L_{n-1}\right) X$. The observed rate constant for the substitution reaction is given by equation 1 , in which $K_{o s}$ is $k_{12} / k_{21}{ }^{24}$

$\mathrm{M}(\mathrm{L})_{\mathrm{n}}+\mathrm{X} \square \mathrm{M}(\mathrm{L})_{\mathrm{n}} \bullet \mathrm{X} \square \mathrm{M}\left(\mathrm{L}_{\mathrm{n}-1}\right) \mathrm{X}$

$k_{\mathrm{obs}}=\left\{\left(\mathrm{k}_{23} \mathrm{~K}_{\mathrm{os}}[\mathrm{X}]\right) /\left(1+\mathrm{K}_{\mathrm{os}}[\mathrm{X}]\right)\right\}+\mathrm{k}_{32}$ equation 1

When the stability of the encounter complex is low, $\mathrm{K}_{\mathrm{os}}[\mathrm{X}]$ will be $<<1$ and $k_{\mathrm{obs}} \approx$ $\mathrm{k}_{23} \mathrm{~K}_{\mathrm{os}}\left[\mathrm{L}^{\mathrm{x}}\right]+\mathrm{k}_{32}$, whereas if $\mathrm{K}_{\mathrm{os}}[\mathrm{X}]$ is $>>1$, $k_{\mathrm{obs}}$ will be governed by the sum of $\mathrm{k}_{23}$ and $\mathrm{k}_{32} \cdot{ }^{24}$ What determines the stability of the encounter complex is the charge of the ligand and $\mathrm{M}(\mathrm{L})_{\mathrm{n}}$. For instance, charged species form more stable encounter complexes than non-charged ones. Ligand substitution in $\left[\mathrm{Ni}\left(\mathrm{H}_{2} \mathrm{O}\right)_{6}\right]^{2+}$ can be used as an example of the influence of the encounter complex stability in kinetics, since when several ligands are compared, it is possible to see that the variation in the encounter complex formation constant $\mathrm{K}_{\mathrm{os}}$ is reflected on the rate constant ( $k_{\mathrm{obs}}$ ), revealing the role of the encounter complex in the kinetics of ligand exchange.

Such analysis can be extended to an enzymatic reaction and substrate bonding and the encounter complex can be called $\mathrm{ES}^{\ddagger}$. Hence, urease catalysis can be divided into four different steps: (1) formation of the ES ${ }^{\neq}$encounter complex, (2) formation of the ES complex from ES ${ }^{\ddagger}$, (3) catalysis and formation of EP, and (4) release of products and regenerated enzyme $(\mathrm{E}+\mathrm{P})$. 


$$
\mathrm{E}+\mathrm{S} \underset{\mathrm{k}_{21}}{\stackrel{\mathrm{k}_{12}}{\rightleftharpoons}} \mathrm{ES}^{\#} \underset{\mathrm{k}_{32}}{\stackrel{\mathrm{k}_{23}}{\rightleftharpoons}} \mathrm{ES}
$$

In the urease system, urea is a non-charged ligand that will substitute at the mostly non charged urease active site, resulting in extremely low stability of $\mathrm{ES}^{\mp}$. Therefore, the analysis of thermodynamic data for the formation of ES must account that it covers two steps of the reaction covering kinetics of $\mathrm{ES}^{\neq}$and ES formation. Krajewska et al have determined the $\Delta \mathrm{S}_{0}, \Delta \mathrm{G}_{0}, \Delta \mathrm{H}_{0}$ for urease and different ligands: urea, phosphate, boric acid, and mercaptoethanol. ${ }^{7,25}$ Besides, the $\Delta \mathrm{V}_{\mathrm{b}}$ was also calculated for urea-urease complex formation. These results are shown in Table 1. All reactions are spontaneous and exergonic with a fairly constant value (between -14 and $-23 \mathrm{~kJ} / \mathrm{mol}$ ), but the entropy of formation of the ES (or EI) complex is quite different from urea and urease inhibitors, indicating a substantial enthalpy-entropy compensation in a process that is largely enthalpy-driven. For instance, all urease inhibitors tested have a larger negative $\Delta \mathrm{S}_{0}$ than the urea-urease complex, indicating that the EI is more ordered than $\mathrm{E}+\mathrm{I}$. Also, observing table 1, it is possible to see that different values of entropy for the ES formation are obtained at different $\mathrm{pHs}$, which would indicate a possible disordering of the initial state when protonation or deprotonation takes place at a group with $\mathrm{pK}_{\mathrm{a}}$ near 6.8. From the $\Delta \mathrm{S}_{0}$ values of $\mathrm{ES}$ formation, it is possible to see that this value is very close to zero, which could be due to the weak bond between urea and the active site, reflecting an almost unchanged system due to the low stability of the encounter complex. In contrast, the inhibitors should form stronger bonds that are compensated by an increase in the entropy of the system, possibly by water release. ${ }^{26,27}$ The number of released waters can only be speculated, but interestingly, in the crystal structure of the inhibited urease, no water molecule can be found coordinated to the nickel centers. The negative entropy obtained for the EI complex also indicates an 
associative mechanism of ligand substitution, meaning that they first coordinate to nickel, and then water is displaced, which goes in contrast to the proposal of water dissociation before urea coordination. ${ }^{7}$ However, ES is indeed positive (at $\mathrm{pH}$ 6.85), and water dissociation should occur before urea coordination.

Table 1. Thermodynamic parameters for ES formation $\left(\mathrm{E}+\mathrm{S} \rightarrow \mathrm{ES}^{\ddagger} \rightarrow \mathrm{ES}\right)$.

\begin{tabular}{|c|c|c|c|c|}
\hline Ligand & $\Delta S^{0}(\mathrm{~J} / \mathrm{mol})$ & $\begin{array}{l}\Delta \mathrm{H}^{0} \\
(\mathrm{~kJ} / \mathrm{mol})\end{array}$ & $\begin{array}{l}\Delta \mathrm{G}^{0} \\
(\mathrm{~kJ} / \mathrm{mol})\end{array}$ & $\begin{array}{l}\Delta \mathrm{V}_{\mathrm{b}} \\
(\mathrm{mL} / \mathrm{mol})\end{array}$ \\
\hline Urea at pH 6.84 & $7 \pm 3$ & $-12 \pm 1$ & $-14 \pm 2$ & $-2 \pm 2$ \\
\hline Urea pH 7 & $0,4 \pm 3$ & $-14 \pm 1$ & $-14 \pm 1$ & - \\
\hline Urea at pH 6.45 & $-0,5 \pm 3$ & $-14 \pm 1$ & $-14 \pm 1$ & - \\
\hline Phosphate at pH 6.45 & $-12 \pm 14$ & $-17 \pm 4$ & $-13 \pm 4$ & - \\
\hline Boric acid & $-63 \pm 21$ & $-42 \pm 6$ & $-23 \pm 6$ & - \\
\hline Mercaptoethanol & $-9 \pm 9$ & $-20 \pm 3$ & $-17 \pm 3$ & - \\
\hline
\end{tabular}

An important data in urea-urease interaction is the difference in volume between $\mathrm{E}+\mathrm{S}$ and ES, which although close to zero could indicate the release of the structural water, ${ }^{7}$ forming an outer sphere encounter complex. Once urea is on the outer sphere encounter complex, it can bind to $\mathrm{Ni}(1)$ since it is pentacoordinate and can still receive an electron pair from urea. The flap closure is dictated by $\alpha$ His323(SPU numbering), ${ }^{28}$ ordering the system and resulting in a large negative entropy of activation (-80 J /mol). ${ }^{29}$ This also enables the concomitant removal of the $\mathrm{Ni}(1)$ coordinated water, resulting in an activation volume of $5 \mathrm{~mL} / \mathrm{mol}$, in agreement with the activation volume of dissociation of one water molecule from $\left.\left[\mathrm{Ni}_{(} \mathrm{H}_{2} \mathrm{O}\right)_{6}\right]^{2+}(7.2 \mathrm{~mL} / \mathrm{mol})$. At this stage, the amide nitrogen from urea can coordinate to $\mathrm{Ni}(2)$ forming a bridge between both nickel centers, as proposed by Benini et $a l^{8}$ or one of the coordinated waters (W2 or WB) could attack the carbonyl as proposed by Zerner and Hausinger. ${ }^{30}$ The acknowledgment of this competition guides to a simple thought: the step that happens faster (catalysis or 
ligand substitution at $\mathrm{Ni}(2)$ ) will lead the reaction. In other words, if the catalytic reaction occurs with the attack of the bridged hydroxide (or W2) faster than the rate of ligand exchange, this would indicate that $\mathrm{Ni}(2)$ would be hydrated during the whole process.

Therefore, the straightforward analysis between $k_{\mathrm{cat}}$ and $k_{\mathrm{ex}}$ can lead to the answer. Taking for instance urease from Jack Bean with $k_{\text {cat }}=2.34 \times 10^{4} \mathrm{~s}^{-1}$ and the water exchange constant value for $\left[\mathrm{Ni}\left(\mathrm{H}_{2} \mathrm{O}\right)_{6}\right]^{2+}$ of $3.2 \times 10^{4} \mathrm{~s}^{-1}$ it is clear that both of these constants are in the same order of magnitude and there is a competition between dehydration of $\mathrm{Ni}(2)$ and catalysis. ${ }^{22,31}$ However, since the experimental thermodynamics does not present reasonable values of activation volumes for the release of two water molecules from the active site, it is most probable that $\mathrm{Ni}(2)$ is acting in its hydrated form. Moreover, if we substitute $\mathrm{Ni}^{2+}$ with any other metal, such as $\mathrm{Fe}^{2+}$, to obtain an iron-based urease, the water exchange rate would be $4.4 \times 10^{6} \mathrm{~s}^{-1}$, which is two orders of magnitude greater than $k_{\text {cat }}$ (of a $\mathrm{Ni}^{2+}$ based urease). This faster water exchange suggests the removal of the competition between dehydration of $\mathrm{Ni}(2)$ and catalysis, and dehydration would take place, enabling the coordination of urea in a bidentate manner. The bidentate coordination mode is able of suffering the attack of the bridged hydroxide, ${ }^{11}$ however, since the second metallic center is not hydrated, proton transfer and regeneration of the catalytic center is hindered, decreasing urease activity dramatically. Following this analysis, the substitution of nickel by the more labile metals $\mathrm{Fe}^{2+}, \mathrm{Co}^{2+}, \mathrm{Mn}^{2+},{ }^{15} \mathrm{Zn}^{2+}$, and $\mathrm{Cu}^{2+}$ would result in a urease enzyme able of coordinating to urea in a bridged mode and the difference between their activities could be explained by different $\mathrm{p} K_{\mathrm{as}}$ of the bridged hydroxide influencing its nucleophilicity. This hypothesis can explain why nickel is the sole preferred metal in urease. 
Now we should answer who is the nucleophile: WB or W2? Krajewska has determined that a group with $\mathrm{pK}_{\mathrm{a}}$ of 8.8 is involved in the catalytic event, assigning it to the bridged hydroxide. ${ }^{32}$ However, no single-bridged hydroxide has been demonstrated to bear a $\mathrm{pK}_{\mathrm{a}}$ of 8.8 . Also, the change in $\mathrm{pH}$ from 8.8 to 9.1 cannot explain why $\mathrm{Mn}^{2+-}$ urease has only $2 \%$ of the $\mathrm{Ni}^{2+}$ restored urease. The $\mathrm{pK}_{\mathrm{a}}$ of other bridged hydroxo groups in bimetallic enzymes are much lower than 8.8. For instance, the $\mathrm{Mn}^{2+}$ dependentphosphotriesterase was shown to have a pH-rate profile dependent on a single ionization of a group with $\mathrm{pK}_{\mathrm{a}} 7.9$ and $7.4 .{ }^{33}$ Also, purple acid phosphatase based on $\mathrm{Fe}^{3+}$ and $\mathrm{Mn}^{2+}$ presents a terminal water group with $\mathrm{pK}_{\mathrm{a}}$ of 3.7 and when a dinuclear $\mathrm{Mn}^{2+}$ active site is present, the $\mathrm{pK}_{\mathrm{a}}$ raises to 6.80 , indicating the presence of an $\mu$-hydroxyl as a nucleophile. ${ }^{34}$ Native $\mathrm{Fe}^{3+}-\mathrm{Fe}^{2+}$ uteroferrin enzyme was also determined to have the terminal $\mathrm{Fe}^{3+}$-bound $\mathrm{H}_{2} \mathrm{O} / \mathrm{OH}^{-}$as the most likely nucleophile, ${ }^{35}$ while for the $\mathrm{Fe}^{3+}-\mathrm{Ni}^{2+}$ derivative, the $\mathrm{p} K_{\mathrm{a}}$ of 4.6 has been assigned to the deprotonation of the $\mu$-hydroxide. ${ }^{13}$ In dihydroorotase, a dinuclear zinc enzyme, a $\mathrm{pK}_{\mathrm{a}}$ of 6.0 was determined and when $\mathrm{Zn}^{2+}$ was replaced by $\mathrm{Co}^{2+}$, the $\mathrm{pK}_{\mathrm{a}}$ was raised to $7.8 .{ }^{6}$ On the other hand, dinuclear nickel compounds were described to bear $\mathrm{pK}_{\mathrm{as}}$ of 4.4 and 8.5 for each of the two bridging water ligands (and not hydroxide). Therefore, the hydroxide in urease should have a $\mathrm{pK}_{\mathrm{a}}$ between 7.8 and 4 , corresponding to the $\mathrm{pK}_{\mathrm{a} 1}$ observed in urease. ${ }^{15}$

Interestingly, a group with $\mathrm{pK}_{\mathrm{a}}$ near 6.6 in jack bean urease has been ascribed to be involved in the binding of urea, ${ }^{36}$ which is disturbed by phosphate. Phosphate is known to be a competitive inhibitor of urease, coordinating in a tridentate mode, ${ }^{37}$ disturbing all coordinated waters, meaning that some of the coordinated waters could have this $\mathrm{pK}_{\mathrm{a}}$. We have shown in table 1 that different values of entropy were obtained at different $\mathrm{pHs}$, possibly related to a group with $\mathrm{pK}_{\mathrm{a}}$ near 6.8. Hence, the group with $\mathrm{pK}_{\mathrm{a}} 6.6$ could be the reason behind why urease has different entropy values (and signs) 
at pHs lower, near, and higher than 6.6. ${ }^{25}$ For instance, the protonation of the hydroxo bridge at $\mathrm{pH} 6.45$ would reduce the ordering of the four centered hydrogen bonding arrangement of the active site water molecules (as shown in Figure 2), ${ }^{38}$ and the displacement of the structural water by urea to form the encounter complex would result in a system with almost the same entropy as the initial state, with a $\Delta \mathrm{S}$ near zero. ${ }^{25} \mathrm{~A}$ similar trend would be observed if deprotonation takes place at $\mathrm{pH} 7$, as shown in Figure 2. Therefore, we propose that the bridged hydroxide in urease has a $\mathrm{pK}_{\mathrm{a}}$ of 6.6.
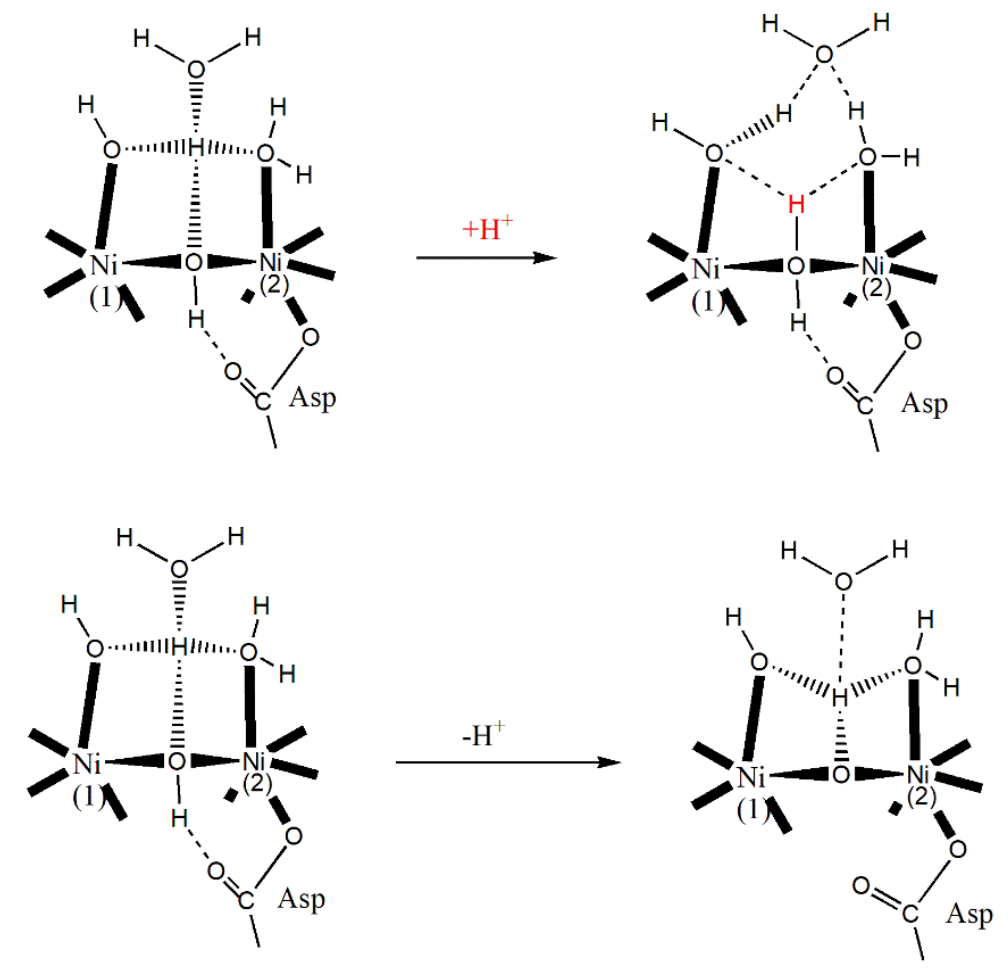

Figure 2. Scheme of the disordering of the system with changes in $\mathrm{pH}$. Protonation and deprotonation of the hydroxide bridge enhances the entropy of the system.

Curiously, some dinuclear metalo-hydrolases exhibit an alkaline shift of the $\mathrm{pK}_{\mathrm{a}}$ of the bridged hydroxide upon substrate binding and the bridging water ligand moves into a pseudomonodentate position. ${ }^{39}$ Therefore, if upon urea coordination to $\mathrm{Ni}(1)$, the hydroxo bridge moves into a pseudomonodentate position, a shift from the $\mathrm{pK}_{\mathrm{a}}$ of 6.6 to 8.8 would be observed. This would enable the nucleophilic attack of the hydroxo- 
bridge to the carbonyl of urea. Proton exchange would be performed by the $\mathrm{Ni}(2)$ bond water, since its $\mathrm{pK}_{\mathrm{a}}$ would be probably lower than the $\mathrm{pK}_{\mathrm{a}}$ of $\left[\mathrm{Ni}\left(\mathrm{H}_{2} \mathrm{O}\right)_{6}\right]^{2+}$ (9.8), owing to its proximity to the carboxyl group of alanine, making strong hydrogen bonds that weaken the O-H bond. ${ }^{8}$ Proton exchange from W2 to the amide nitrogen facilitates the formation of ammonia (step 3, Figure 3). The resulting hydroxide should attack Ni1 to easily regenerate the active site (step 4, Figure 3). This mechanism also explains 
fluoride acting as an uncompetitive inhibitor related to enzyme turnover. ${ }^{40}$

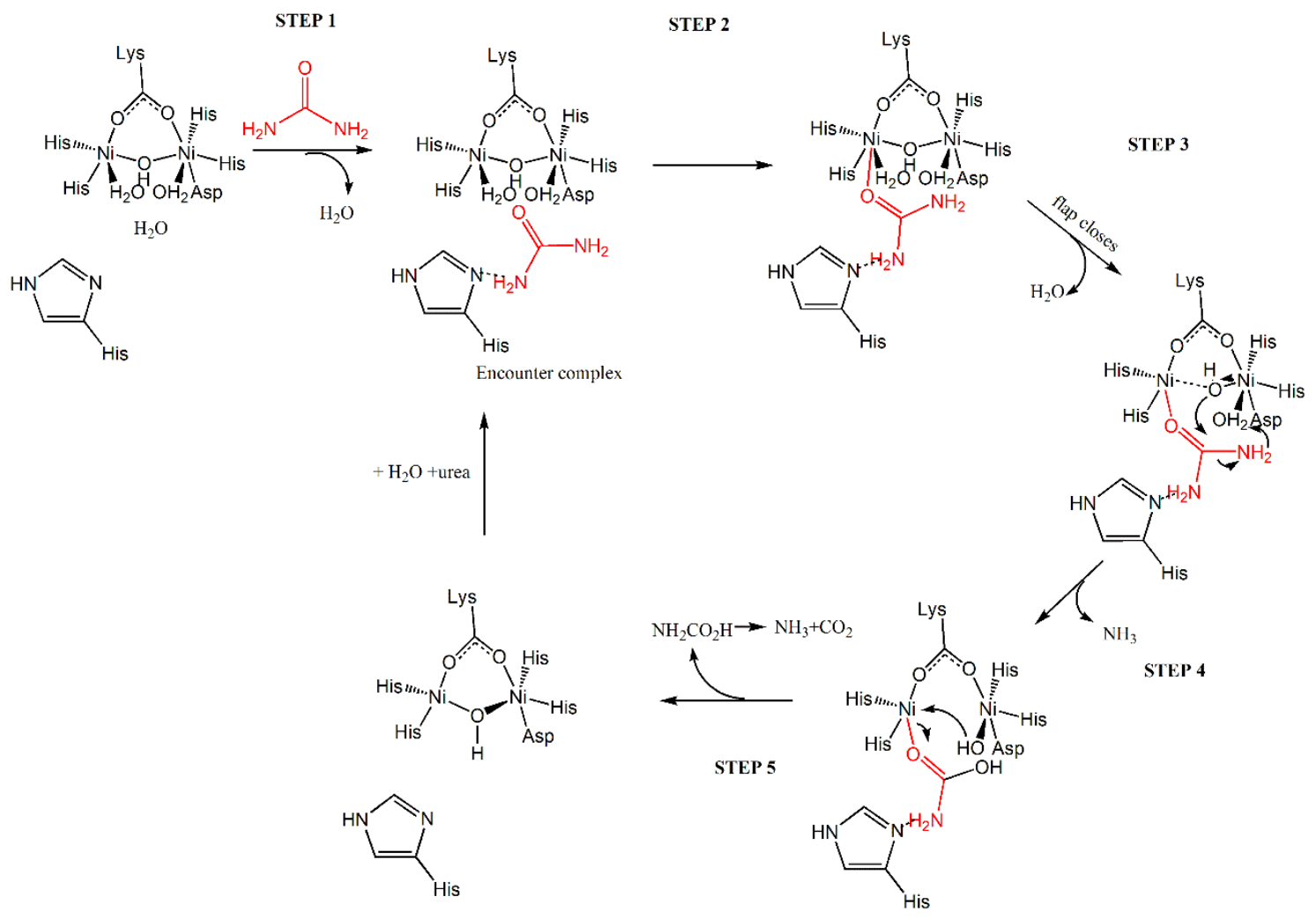

Figure 3. Mechanism proposal of urease. First urea forms a urea-urease encounter complex, then water from $\mathrm{Ni}(1)$ is removed concomitantly with flap closure. A shift from bridged to pseudo-monodentate coordination mode of the hydroxide explains the 
high $\mathrm{pK}_{\mathrm{a}}$ observed for this moiety. Proton exchange from $\mathrm{Ni}(2)$ bond water enables ammonia formation, whereas the $\mathrm{Ni}(2)$ hydroxide attacks $\mathrm{Ni}(1)$ to regenerate the active site.

This assumption contradicts the reverse protonation hypothesis, which proposes that His320 (in Klebsiella aerogenes numbering) is a general acid that enables catalysis in a reverse protonation. However, the reverse protonation relies on the probability of a fraction of the enzyme to be protonated in a manner opposite (or reverse) from what one would expect given the $\mathrm{p} K_{\mathrm{as}}$ of the free amino acids. ${ }^{41}$ It was previously thought that His320 had a $p K_{a}$ of 6.5 , which would result in only $0.3 \%$ of all urease molecules being in the optimal protonation state for catalysis. ${ }^{41}$ However, a $\mathrm{p} K_{a}$ of 5.0 was assigned to this histidine residue, which should participate in substrate binding and catalytic reaction. ${ }^{32}$ This smaller $\mathrm{p} K_{a}$ would almost prohibit the reverse protonation and the catalytic feature of histidine should most probably be acting as a general base. Moreover, His323 (SPU numbering) is essential for the flap movement, ${ }^{42}$ therefore, without this residue, the catalytic activity is dramatically dropped. ${ }^{43}$ Also, if the flap is open, the water displacement from $\mathrm{Ni}(1)$ probably does not occur, which would keep the $\mathrm{pK}_{\mathrm{a}}$ of the bridged hydroxide at 6.6, explaining the $\mathrm{pH}$ profile of several mutants. For instance, mutant $\alpha \mathrm{H} 320 \mathrm{~A}$ (KAU numbering) exhibited a significantly shifted $\mathrm{pH}$ optimum at around $6.75 .^{43}$ It is known that a constellation of groups with different $\mathrm{pK}_{\mathrm{as}}$ is involved in catalysis and that our hypothesis could be a simplistic view and care should be taken. ${ }^{44}$ However, the $\mathrm{pK}_{\mathrm{a}}$ shift of the hydroxide from 6.6 to 8.8 would also explain the presence of two distinct active states in urease with different optimum $\mathrm{pHs},{ }^{45}$ evidencing the competition between $\mathrm{k}_{\mathrm{cat}}$ and $\mathrm{k}_{\mathrm{ex}}$, as shown in figure 4 . For instance, the increase of ionic strength of the medium should affect negatively on $\mathrm{k}_{\mathrm{cat}}$ for the high $\mathrm{pH}$ 
state owing to the neutralization of the charges involved in the flap closure, ${ }^{28}$ increasing the possibility of a bridged $\mathrm{O}, \mathrm{N}$ urea bonding. In addition, taking as an example the substitution of His219 (KAU numbering), it is seen that charged residues, such as glutamine or asparagine, had a much higher impact on the $\mathrm{pH}$ profile than H219A mutant, with a described possible misorientation of His320 in these proteins, causing a shift on the flap. This flap shift could increase the bridged $\mathrm{O}, \mathrm{N}$ urea bonding mode increasing the low $\mathrm{pH}$ profile of activity. Also, the mutation in aspartate, D221A, shows an open flap and more density associated with the bridging water, explaining the observed activity at lower $\mathrm{pH} .^{44}$
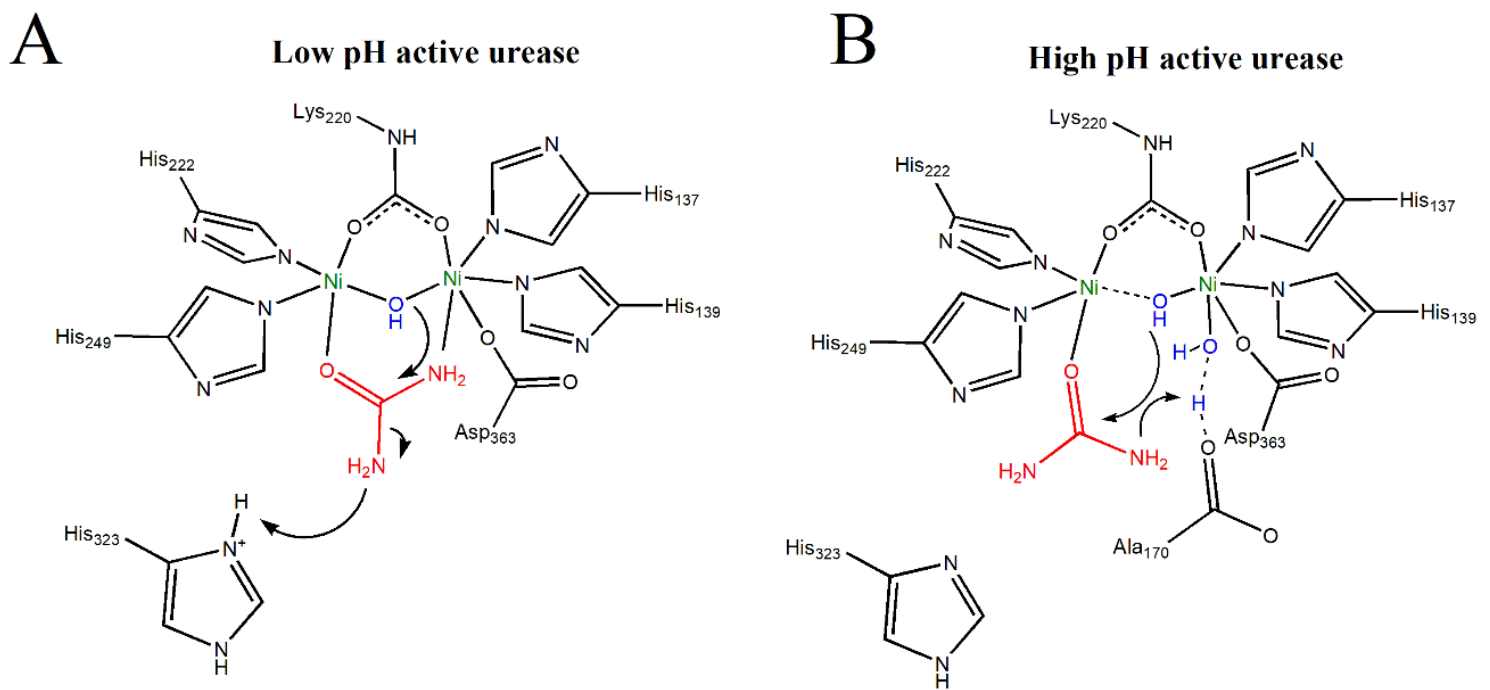

Figure 4. Two active states of urease. (A) The low $\mathrm{pH}$ active urease involves urea coordination in a bridged mode and the nucleophilic attack of the bridged hydroxyl with pKa 6.6. (B) The shift from bridged to pseudo-monodentate coordination mode of the hydroxide explains the high $\mathrm{pK}_{\mathrm{a}}$ observed for this moiety. Proton exchange from $\mathrm{Ni}(2)$ bond water enables ammonia formation, whereas the $\mathrm{Ni}(2)$ hydroxide attacks $\mathrm{Ni}(1)$ to regenerate the active site. 
These facts allowed us to propose a new model of urease activity based on a literature review, indicating that the competition between $\mathrm{k}_{\text {cat }}$ and $\mathrm{k}_{\mathrm{ex}}$ might also be happening in other enzymes.

\section{Conclusion}

In this analysis, we verified the role of the competition between metal lability and reaction rate in the determination of a metalloenzyme mechanism. This competition is the basis for urea selectivity towards nickel since it disables (or enables) urea coordination in a bridged mode. We have also re-analyzed the data regarding $\mathrm{pK}_{\mathrm{a}}$ to explain the role of histidine 320 and the bridged hydroxyl in the reaction $\mathrm{pH}$. With this mechanism proposal, we can explain the thermodynamic data, the formation of ES, the competition between catalysis and dehydration of $\mathrm{Ni}(2)$, the $\mathrm{pK}_{\mathrm{as}}$ involved in catalysis, the fast regeneration of the system, the fluoride action as an uncompetitive inhibitor related to the turnover of the enzyme and finally, why urease uses nickel instead of other metals.

\section{Acknowledgment}

We would like to kindly thank CNPq (141677/2019-8) and CAPES (88882.332767/2019-01) for the Ph.D. fellowships. We would also like to thank CAPES project 001 . This research had no other funding, despite the requirement of the financial support agencies for productivity.

\section{References}

(1) Eom, H.; Song, W. J. Emergence of Metal Selectivity and Promiscuity in Metalloenzymes. J. Biol. Inorg. Chem. 2019. 24, 517-531.

(2) Valasatava, Y.; Rosato, A.; Furnham, N.; Thornton, J. M.; Andreini, C. To What 
Extent Do Structural Changes in Catalytic Metal Sites Affect Enzyme Function? J. Inorg. Biochem. 2018. 179, 40-53.

(3) Seibert, C. M.; Raushel, F. M. Structural and Catalytic Diversity within the Amidohydrolase Superfamily. Biochemistry. 2005. 44, 6383-6391.

(4) Ciurli, S.; Benini, S.; Rypniewski, W. R.; Wilson, K. S.; Miletti, S.; Mangani, S. Structural Properties of the Nickel Ions in Urease: Novel Insights into the Catalytic and Inhibition Mechanisms. Coord. Chem. Rev. 1999. 190-192, 331355.

(5) Jabri, E.; Carr, M. B.; Hausinger, R. P.; Karplus, P. A. The Crystal Structure of Urease from Klebsiella Aerogenes. Science. 1995. 268, 998-1004.

(6) Porter, T. N.; Li, Y.; Raushel, F. M. Mechanism of the Dihydroorotase Reaction. Biochemistry. 2004. 43, 16285-16292.

(7) Krajewska, B.; Van Eldik, R.; Brindell, M. Temperature- and Pressure-Dependent Stopped-Flow Kinetic Studies of Jack Bean Urease. Implications for the Catalytic Mechanism. J. Biol. Inorg. Chem. 2012. 17, 1123-1134.

(8) Benini, S.; Rypniewski, W. R.; Wilson, K. S.; Miletti, S.; Ciurli, S.; Mangani, S. A New Proposal for Urease Mechanism Based on the Crystal Structures of the Native and Inhibited Enzyme from Bacillus Pasteurii: Why Urea Hydrolysis Costs Two Nickels. Structure 1999. 7, 205-216.

(9) Mazzei, L.; Cianci, M.; Benini, S.; Ciurli, S. The Structure of the Elusive Urease-Urea Complex Unveils the Mechanism of a Paradigmatic NickelDependent Enzyme. Angew. Chemie - Int. Ed. 2019. 58, 7415-7419.

(10) Mazzei, L.; Musiani, F.; Ciurli, S. The Structure-Based Reaction Mechanism of Urease, a Nickel Dependent Enzyme: Tale of a Long Debate. J. Biol. Inorg. Chem. 2020. 58, 7415-7419.

(11) Carter, E. L.; Tronrud, D. E.; Taber, S. R.; Karplus, P. A.; Hausinger, R. P. IronContaining Urease in a Pathogenic Bacterium. Proc. Natl. Acad. Sci. U. S. A. 2011. 108, 13095-13099.

(12) Carter, E. L.; Flugga, N.; Boer, J. L.; Mulrooney, S. B.; Hausinger, R. P. Interplay of Metal Ions and Urease. Metallomics. 2009. 1, 207-221.

(13) Schenk, G.; Peralta, R. A.; Batista, S. C.; Bortoluzzi, A. J.; Szpoganicz, B.; Dick, A. K.; Herrald, P.; Hanson, G. R.; Szilagyi, R. K.; Riley, M. J.; et al. Probing the Role of the Divalent Metal Ion in Uteroferrin Using Metal Ion Replacement and a Comparison to Isostructural Biomimetics. J. Biol. Inorg. Chem. 2008. 13, 139155.

(14) Brown, D. C.; Collins, K. D. Dihydroorotase from Escherichia Coli. Substitution of Co(II) for the Active Site Zn(II). J. Biol. Chem. 1991. 266, 1597-1604.

(15) Yamaguchi, K.; Cosper, N. J.; Stålhandske, C.; Scott, R. A.; Pearson, M. A.; Karplus, P. A.; Hausinger, R. P. Characterization of Metal-Substituted Klebsiella Aerogenes Urease. J. Biol. Inorg. Chem. 1999. 4, 468-477. 
(16) Laird, B. D.; Peak, D.; Siciliano, S. D. Bioaccessibility of Metal Cations in Soil Is Linearly Related to Its Water Exchange Rate Constant. Environ. Sci. Technol. 2011. 45, 4139-4144.

(17) Lee, Y.; Thirumalai, D.; Hyeon, C. Ultrasensitivity of Water Exchange Kinetics to the Size of Metal Ion. J. Am. Chem. Soc. 2017. 139, 12334-12337.

(18) Waegele, M. M.; Gunathunge, C. M.; Li, J.; Li, X. How Cations Affect the Electric Double Layer and the Rates and Selectivity of Electrocatalytic Processes. J. Chem. Phys. 2019. 151, 160902.

(19) Remsing, R. C.; Klein, M. L. Exponential Scaling of Water Exchange Rates with Ion Interaction Strength from the Perspective of Dynamic Facilitation Theory. $J$. Phys. Chem. A 2019. 123, 1077-1084.

(20) Remsing, R. C.; McKendry, I. G.; Strongin, D. R.; Klein, M. L.; Zdilla, M. J. Frustrated Solvation Structures Can Enhance Electron Transfer Rates. J. Phys. Chem. Lett. 2015. 6, 4804-4808.

(21) Haider, K.; Wickstrom, L.; Ramsey, S.; Gilson, M. K.; Kurtzman, T. Enthalpic Breakdown of Water Structure on Protein Active-Site Surfaces. J. Phys. Chem. B 2016. 120 , 8743-8756.

(22) Helm, L.; Merbach, A. E. Water Exchange on Metal Ions: Experiments and Simulations. Coord. Chem. Rev. 1999. 187, 151-181..

(23) Huang, C. Y.; Hsu, C. C.; Chen, M. C.; Yang, Y. S. Effect of Metal Binding and Posttranslational Lysine Carboxylation on the Activity of Recombinant Hydantoinase. J. Biol. Inorg. Chem. 2009. 14, 111-121.

(24) Richens, D. T. Ligand Substitution Reactions at Inorganic Centers. Chem. Rev. 2005. 105, 1961-2002.

(25) Krajewska, B.; Brindell, M. Thermodynamic Study of Competitive Inhibitors' Binding to Urease. J. Therm. Anal. Calorim. 2016. 123, 2427-2439.

(26) Dragan, A. I.; Read, C. M.; Crane-Robinson, C. Enthalpy-Entropy Compensation: The Role of Solvation. Eur. Biophys. J. 2017. 46, 301-308.

(27) Debnath, A.; Mukherjee, B.; Ayappa, K. G.; Maiti, P. K.; Lin, S. T. Entropy and Dynamics of Water in Hydration Layers of a Bilayer. J. Chem. Phys. 2010. 133, 174704.

(28) Mazzei, L.; Cianci, M.; Benini, S.; Ciurli, S. The Impact of PH on Catalytically Critical Protein Conformational Changes: The Case of the Urease, a Nickel Enzyme. Chem. - A Eur. J. 2019. 25, 12145-12158.

(29) Roberts, B. P.; Miller, B. R.; Roitberg, A. E.; Merz, K. M. Wide-Open Flaps Are Key to Urease Activity. J. Am. Chem. Soc. 2012. 134, 9934-9937.

(30) Karplus, P. A.; Pearson, M. A.; Hausinger, R. P. 70 Years of Crystalline Urease: What Have We Learned? Acc. Chem. Res. 1997. 30, 330-337.

(31) Blakeley, R. L.; Webb, E. C.; Zerner, B. Jack Bean Urease (EC 3.5.1.5). A New 
Purification and Reliable Rate Assay. Biochemistry 1969. 8, 1984-1990.

(32) Krajewska, B. A Combined Temperature-PH Study of Urease Kinetics. Assigning PKa Values to Ionizable Groups of the Active Site Involved in the Catalytic Reaction. J. Mol. Catal. B Enzym. 2016. 124, 70-76.

(33) Bigley, A. N.; Xiang, D. F.; Narindoshvili, T.; Burgert, C. W.; Hengge, A. C.; Raushel, F. M. Transition State Analysis of the Reaction Catalyzed by the Phosphotriesterase from Sphingobium Sp. TCM1. Biochemistry 2019. 58, 12461259.

(34) Mitić, N.; Noble, C. J.; Gahan, L. R.; Hanson, G. R.; Schenk, G. Metal-Ion Mutagenesis: Conversion of a Purple Acid Phosphatase from Sweet Potato to a Neutral Phosphatase with the Formation of an Unprecedented Catalytically Competent MnIIMnII Active Site. J. Am. Chem. Soc. 2009. 131, 8173-8179.

(35) Smith, S. J.; Casellato, A.; Hadler, K. S.; Mitić, N.; Riley, M. J.; Bortoluzzi, A. J.; Szpoganicz, B.; Schenk, G.; Neves, A.; Gahan, L. R. The Reaction Mechanism of the Ga(III)Zn(II) Derivative of Uteroferrin and Corresponding Biomimetics. J. Biol. Inorg. Chem. 2007. 12, 1207-1220.

(36) Krajewska, B.; Ciurli, S. Jack Bean (Canavalia Ensiformis) Urease. Probing Acid-Base Groups of the Active Site by PH Variation. Plant Physiol. Biochem. 2005. 43, 651-658.

(37) Benini, S.; Rypniewski, W.; Wilson, K.; Ciurli, S.; Mangani, S. Structure-Based Rationalization of Urease Inhibition by Phosphate: Novel Insights into the Enzyme Mechanism. J. Biol. Inorg. Chem. 2001. 6, 778-790.

(38) Hausinger, R. P.; Karplus, P. A. Urease. Encyc. Inorg. Bioinorg. Chem. American Cancer Society, 2011. 1-14.

(39) Pedroso, M. M.; Selleck, C.; Enculescu, C.; Harmer, J. R.; Mitić, N.; Craig, W. R.; Helweh, W.; Hugenholtz, P.; Tyson, G. W.; Tierney, D. L.; et al. Characterization of a Highly Efficient Antibiotic-Degrading Metallo- $\beta$-Lactamase Obtained from an Uncultured Member of a Permafrost Community. Metallomics 2017. 9, 1157-1168.

(40) Todd, M. J.; Hausinger, R. P. Fluoride Inhibition of Klebsiella Aerogenes Urease: Mechanistic Implications of a Pseudo-Uncompetitive, Slow-Binding Inhibitor. Biochemistry 2000. 18, 5389-5396.

(41) Sims, P. A.; Larsen, T. M.; Poyner, R. R.; Cleland, W. W.; Reed, G. H. Reverse Protonation Is the Key to General Acid - Base Catalysis in Enolase. Biochemistry 2003. 42, 8298-8306.

(42) Macomber, L.; Minkara, M. S.; Hausinger, R. P.; Merz, K. M. Reduction of Urease Activity by Interaction with the Flap Covering the Active Site. J. Chem. Inf. Model. 2015. 55, 354-361.

(43) Park, I. -S; Hausinger, R. P. Site-directed Mutagenesis of Klebsiella Aerogenes Urease: Identification of Histidine Residues That Appear to Function in Nickel Ligation, Substrate Binding, and Catalysis. Protein. Sci. 1993. 2, 1034-1041. 
(44) Pearson, M. A.; Park, I. S.; Schaller, R. A.; Michel, L. O.; Karplus, P. A.; Hausinger, R. P. Kinetic and Structural Characterization of Urease Active Site Variants. Biochemistry 2000. 39, 8575-8584.

(45) Mulrooney, S.; Schaller, R. A.; Hausinger, R. P. Dual Effects of Ionic Strength on Klebsiella Aerogenes Urease: PH-Dependent Activation and Inhibition. Arch. Biochem. Biophys. 2001. 394, 280-282. 